\title{
How Young People Communicate-A Czech Perspective
}

\author{
Eddie Fisher (Corresponding author) \\ Faculty of Social Sciences, Universidad de Oriente, Santiago de Cuba, Cuba \\ 8 Kendal, Swindon, Wiltshire, SN5 8HW, United Kingdom
}

Tel: 44-179-349-0423Ｅ-mail: eddie.fisher9@ btinternet.com

Pavlína Rupová and Dominika Bittnerová

Palacky University, Olomouc, Czech Republic

Received: November 13, 2014 Accepted: November 24, 2014

doi:10.5296/ber.v4i2.6535 URL: http://dx.doi.org/10.5296/ber.v4i2.6535

\begin{abstract}
There appears to be a relationship between the latest communications technology and how effectively young people communicate. It is a world-wide phenomenon. This research investigates how young people in the Czech Republic communicate today in an era of increased use of social media and mobile technology. The research was limited to the city of Olomouc. Results suggest that face to face communications by and amongst young people are diminishing fast at the expense of social media such as Facebook and What's App and sending SMS text messages. This trend could have adverse affects in future on how well young and older people live and work together within their communities. The outcome of this research suggests that proactive steps should be taken now to educate young people in the appropriate use of mobile technology and social media. It would ensure that they retain their ability to communicate effectively not just with their peer groups but also with other age groups and with people from other cultures. Social IPsychology/Psychology needs to take a much more proactive role to address this issue so that the lives of people at all ages can be improved. The outcomes of this research should be of interest to other countries, too, as this phenomenon is not limited to the Czech Republic.
\end{abstract}

Keywords: Effective Communication, Communication Style, Attitude and Behaviour, Social Media, Mobile Technology 


\section{Introduction}

\subsection{Introduction}

Young people across the world have been influenced how they communicate with others by advances in mobile technology and social media. Gone have the days when young people would sit around the table, for example, with their elders and listen and learn from the life experiences of older people. This is particularly true to say in countries and within local communities within these countries where the livelihood of people depends on how well people communicate. It appears that the modus communicandi (how people communicate) is of paramount importance to the quality of social lives of people and that it is highly desirable that young people retain or regain this ability to communicate effectively through the spoken word. Recent research by Fisher (2013) reports that new technology has changed people's lives forever and that it is possible that this situation cannot be reversed. Young people today see it to be their right to have access to this new technology whenever and wherever they want it. Digital communication has grown at such a fast rate that most people are finding it impossible to catch up with it. Fisher and Santana Gonzalez (2014) conducted some research recently to ascertain how young people in Cuba communicate. They found some hard evidence that suggests that young people in Cuba have already started to communicate differently with their peers and elders compared to, for example, how they communicated some 10 or 15 years ago. An emerging country such as the Czech Republic has seen a significant increase in advanced technology in areas such as mobile telephony and social media.

How young people communicate in the Czech Republic has now become a major interest for psychologists/social psychologists. The communication style, for example, of how young people communicate has a major impact on their work and life balance and how they interact with other people. In turn, this impacts on the development of communities in rural and communal areas. Advances in mobile technology and the subsequent creation of associated social media such as Facebook, Twitter and WhatsApp Messenger provide a plethora of opportunities for communicating with friends and family, for example, at the touch of a button rather than face to face. It is this apparent shift in how young people in the Czech Republic communicate that has captured the attention of social psychologists such as the researchers of this research whose aim is to improve the social lives of people. Therefore, the aim and objectives of this research are to investigate how young people in the Czech Republic communicate today and to gather new insights how young people might communicate in future. In addition, this research reports on the associated topics of what makes communications effective and what is meant by intercultural communication. According to Giant (2013), the widespread use of this new technology has had a major impact on how people communicate irrespective of their cultural backgrounds. Young people have grown up with this technology and have never experienced a life without it. It has become part of their daily lives. They can now communicate with anyone anywhere in the world almost instantly by using services such as SMS, E-mail, Skype or social media. Most households now have at least access to one computer (laptop, tablet or work station) with most young people owning a mobile or smart phone. There is unlimited access to information that can be shared with anyone immediately anywhere in the world (Rogers, 2010). In contrast, older people perhaps have developed a 
sense of caution not to trust technology blindly. They appear to rely heavily on how they used to communicate in their younger days such as face to face and having discussions within their local communities. Younger people do not have this balanced view. They were born and grew up in a world that was and is full of technological advances.

It appears that personalities of people are positively influenced by how people communicate in that:

- Communications are one road that lead to the formation of people's personalities in social psychological terms

- They provide consistent emotional intelligence to individuals as well as groups of people

- Good communications are a trademark of active and positive participation that make a contribution to the quality outputs of fellow people

- Effective communications are educational

This research assessed associated psychological constructs such as attitude and behaviour. The researchers have adopted the following definitions within the context of this research:

"Attitude is a mental state of readiness, learned and organised through experience, exerting a specific influence on a person's response to people, objects, and situations with which it is related. Attitudes are determinants of behaviour because they are linked to perception, personality and motivation" (Ivancevich and Matteson, 1992)

"Behaviour is a generic term covering acts, activities, responses, reactions, movements, processes and operations, in other words, any measurable response of an organism"(Reber, 1995)

"Competence refers to areas of work at which the person is competent, the so-called areas for competence. The dimensions of behaviour that underpin a competent performance are referred to as person-related" (Moore, Cheng and Dainty, 2002)

Attitudes and behaviours people can actually observe, alone or with others, and where they can see the effects the applications of these have on other people, must be of greater value than being able to only experience these in the mind (positivist research approach). The researchers applied a constructivist interpretivist approach within a phenomenological research paradigm so they can make a valid and reliable contribution to knowledge that is of value to both academics and practitioners. Fig. 1 is a diagrammatical illustration that shows the most important elements that have an influence on how young people in the Czech Republic communicate today. The researchers adopted the following definitions in the context of this research of what makes effective communications:

'Effective application of psychologically and socially competent verbal and nonverbal abilities and skills in the area of interpersonal and professional contacts and relationships' (http://slovnik-cizich-slov.abz.cz/web.php/slovo/efektivni-komunikace) 


\section{Macrothink}

Business and Economic Research

ISSN 2162-4860

2014, Vol. 4, No. 2

'A communication between human beings if effective when meanings have been transmitted and received as intended' (Maletzke, G. (1976)

The researchers' own definitions of what makes a communication effective are as follows:

'Effective communication is a process when messages are exchanged between a sender and a receiver (coder and decoder). This includes the sharing of information, attitudes, ideas and emotions through mutual feedback. Effective communications take place when two parties are able to exchange views and ideas in such a way that each party understands the intended meaning and acts in accordance with it. This can include but is not limited to persuasive, direct or pleasant language. The feedback that takes place between the two parties makes a contribution towards ensuring that, for example, tasks are carried out correctly and that real life conflicts are resolved satisfactorily'.

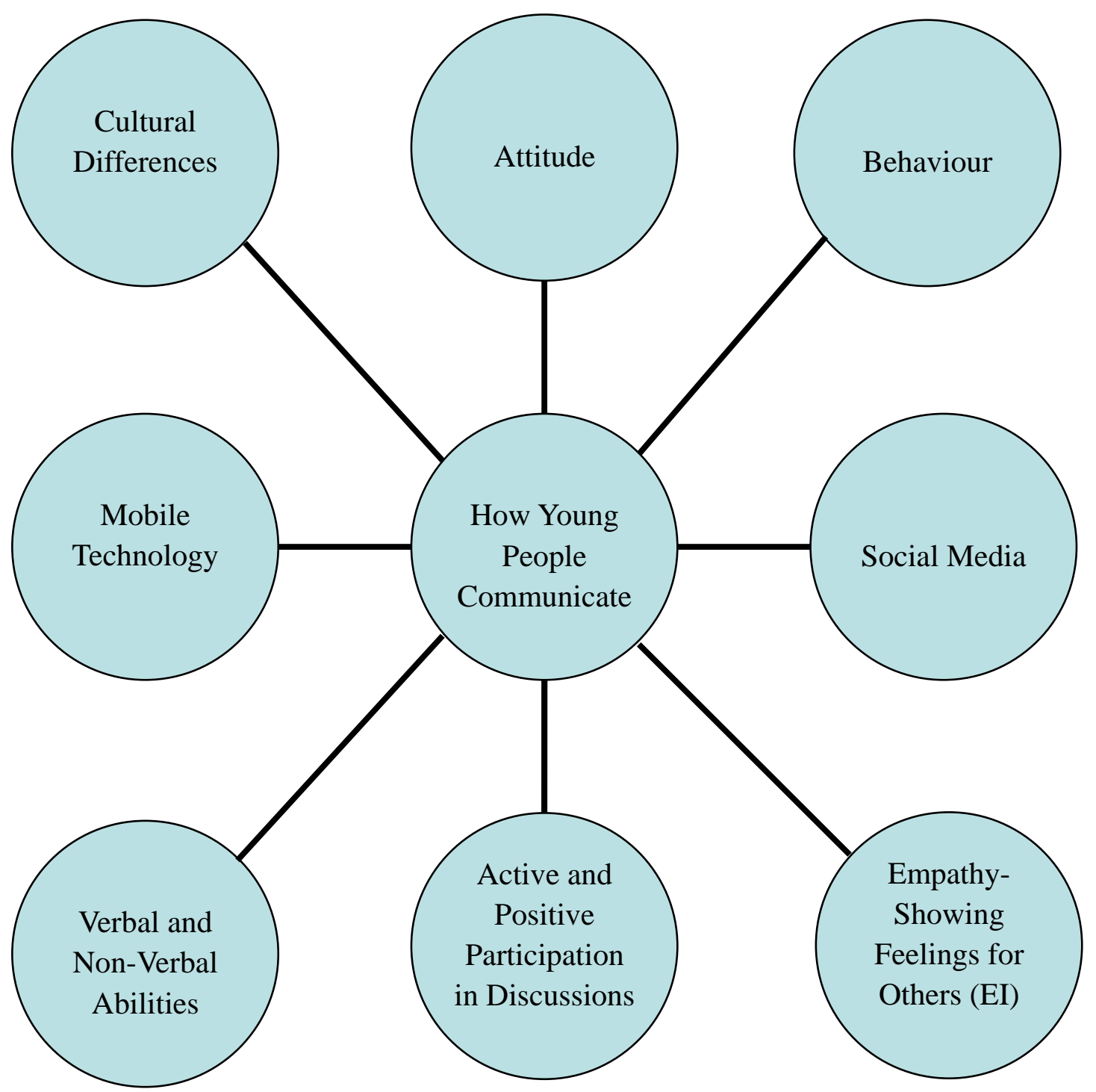

Fig.1 Elements of Effective Communications

A review of contemporary literature is presented next, followed by the main research questions. 


\section{Macrothink}

This forms the theoretical framework of this research and is followed by a presentation of the results from the literature review and face to face interviews with students of psychology/social psychology in Olomouc in the Czech Republic. The research methodology follows which includes data interpretation and analysis. The research results and a discussion of what the research found are presented next. This is concluded in the final section which includes this research's limitations and suggestions for future research.

\subsection{Literature Review}

Rogers and Steinfatt (1999) argue that the principle of communication is a process. Everyone communicates in such as way that all parties understand each other as intended. Human beings communicate with each other as soon as they are born. This is essential for human well being and to develop social relationships and the personalities of human beings. Communication is an iterative process. It builds on previous experiences to shape future exchanges, thus building a communication process that is developed over time (Fig.2). According to Rogers and Steinfatt language is the fundamental building block to all effective communications. Human beings use language to think and to speak. The perceptions people hold are represented in their communications. Verbal communications appears to be more effective than non-verbal communications as it is possible to convey clearer and more exact meanings through the spoken word in line with cultural differences of the audience. It is much easier to control verbal communication than non-verbal communications. Observing someone's body language and/or gesturing during communications tell the truth what the other party is really saying.

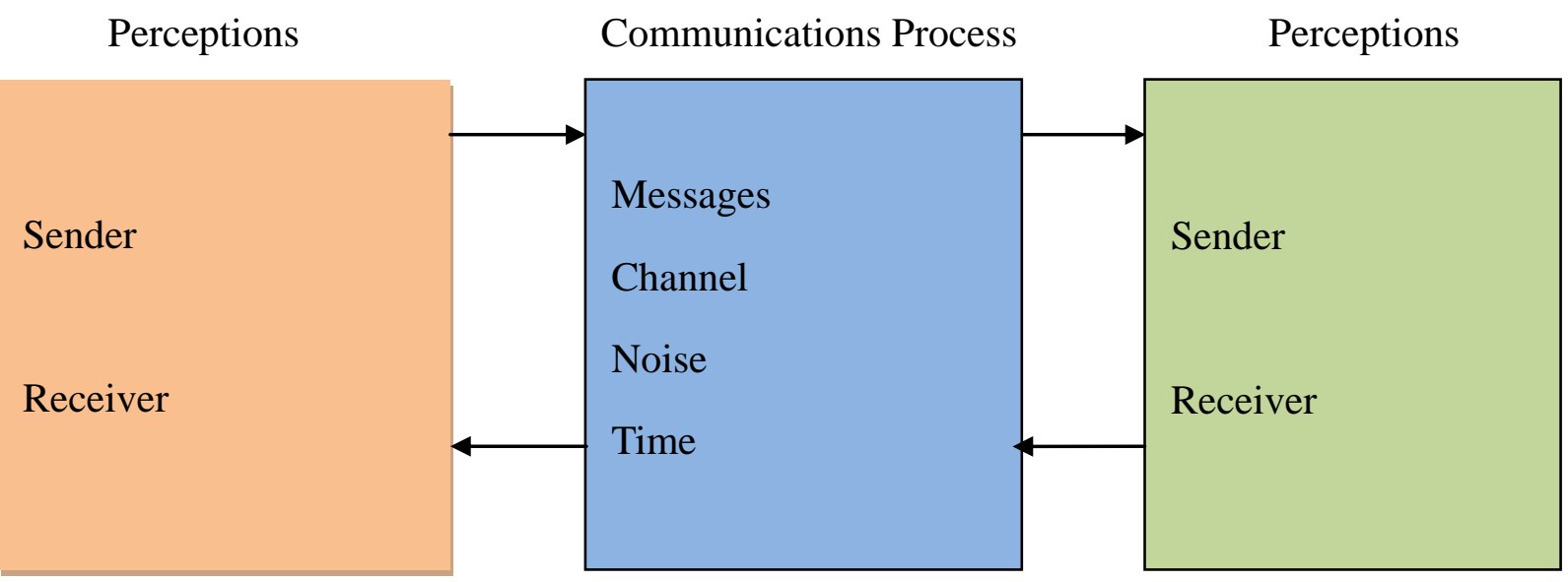

Fig. 2 Communication Environment Model (adapted from Rogers et al., 1998, p. 15)

Hall (1966) claims that non-verbal communication is another language he refers to as a silent language. In contrast, critics suggest that non-verbal communication is a code that can be decoded and then reveal the true nature of people. Reality suggests otherwise. Rogers and Steinfatt report that non-verbal communication 'is a field of multiple nuances which we have only begun to explore' (p. 162). People, for example, look at the clothing and behaviour of people and then make decisions whether to start verbal communication with these people. Hall considers that non-verbal communication provides a more reliable basis for building trust. People cannot easily control their body language and gestures and this lack of control over their non-verbal communication is perceived to be a more reliable predictor of levels of trust people 
can have in others. Hall reports that the use of non-verbal symbols differs from culture to culture and that this is similar to languages. It is important to understand the non-verbal communication codes for each culture to ensure that effective communication can take place. Dinica (2014) proposes that the importance of body language should not be underestimated. Mimicking sometimes conveys a whole story. Appropriate application of body language such as Charlie Chaplin's facial expressions makes words unnecessary. This explains why experienced people prefer to communicate face to face rather than by telephone. Telephone conversations block opportunities to observe the body language of the other person(s) and as such any such communication is incomplete and uncertain (Ury, 1994; Stanton, 1997). Pinto et al. (2012) conducted some research in the medical area to establish if patient-centred communication does lead to a positive therapeutic alliance. Their study concluded that active listening, asking questions and showing empathy strengthened the therapeutic alliance with patients. In addition, using appropriate verbal and non-verbal communication styles improved the effective communications with patients.

Thomson (1996) conducted some research to ascertain what makes a communication effective. It appears that people are not actively listening due to the fact that they get distracted by other things around them or not keeping a good eye contact with the person they are communicating with. If a communication is important, then people need to listen more actively to the person they wish to communicate with. To improve effective communication, Thomson suggests a number of actions people can take to improve their active listening skills. Table 1 is a summary of considerations why people do not listen, when people do need to listen and some steps of active listening. Thomson suggests 'that the art of conversation is to be interested, not interesting' (page 14). This includes maintaining regular and good eye contact with the other person or persons. Eye contact allows the communicator to check how others perceive what has just been said and the effect this has had on the other person or persons. A lack of eye contact suggests that the other person may not be genuinely interested in a conversation or that they are not telling the truth. People who understand body language are generally considered to be more effective communicators. Table 1 is a summary of some typical body gestures from everyday life.

Table 1 Body Language Gestures (Source: Thomson, 1996)

\begin{tabular}{|c|c|}
\hline Gesture & Impact \\
\hline $\begin{array}{l}\text { Leaning } \begin{array}{r}\text { forward } \\
\text { towards the other } \\
\text { person }\end{array} \\
\end{array}$ & They feel comfortable and are interested in what is being said \\
\hline $\begin{array}{l}\text { Leaning away from } \\
\text { the other person }\end{array}$ & The person does not feel comfortable with what has been said \\
\hline $\begin{array}{l}\text { Crossed arms and } \\
\text { crossed legs }\end{array}$ & $\begin{array}{l}\text { Indicates that the person usually feels negative or defensive about the situation they } \\
\text { are in or about what they have just heard (can sometimes also mean that people simply } \\
\text { feel comfortable or feel cold) }\end{array}$ \\
\hline $\begin{array}{l}\text { Hand behind the head } \\
\text { and rocking the chair }\end{array}$ & Indicates a 'You cannot hurt me' or 'You cannot fool me' gesture \\
\hline $\begin{array}{l}\text { Hands being rubbed } \\
\text { together quickly } \\
\text { Hands being rubbed } \\
\text { together slowly }\end{array}$ & $\begin{array}{l}\text { Indicates enthusiasm or that the speaker believes that what he is saying will be of } \\
\text { benefit to the listener } \\
\text { Indicates nervousness and the person is possibly deceitful }\end{array}$ \\
\hline
\end{tabular}


\begin{tabular}{|l|l|}
\hline Chin Stroking & The person is thinking about what to say next or is making a decision \\
\hline
\end{tabular}

Hands behind the Indicates that the person is confident

back

Chiper (2013) argues that intercultural communications has established itself as a life skill. As a result, more higher education establishment such as colleges and universities offer courses specifically for developing the intercultural communication skills of young people. This view is shared by Popescu et al. (2014) who suggest that it has become essential in relation to today's societal structure and make-up to take pro-active steps to strengthen intercultural communications and close working relationships between individuals and groups made up of many different ethnic backgrounds (Chevrier, 2003; Bakir et al, 2004; Cox and Blake, 1991; Goodall and Roberts, 2003). Popescu et al argue that the ability to communicate well at intercultural level is going to be a key skill to have for those who lead groups of people, particularly at local community level. Cultural diversity is of enormous value but this needs to be communicated effectively and appropriately: 'Cultural diversity is a promising phenomenon of wealth whose exploration could bring incalculable benefit' (Lewis, 1996). Jandt (2001) suggests that a non-verbal communication style can work quite well during intercultural communications. Non-spoken symbols replace the spoken word and this can aid understanding during intercultural communications, particularly where language limitations are prevalent. An example is an arrow pointed in a certain direction to show, for example, passengers at the airport where to go or a wheel-chair sign in car parks to show where designated car parking spaces are located for those with special needs. At work, more senior and experienced people use non-verbal communications in a relaxed way which often indicates their hierarchical status. According to Jandt, 'Understanding and using non-verbal symbols are part of the communicating skills of a competent intercultural communicator' (p.106). In contrast, Jandt suggests that language is used by communities to ensure that what has been communicated has been clearly understood as intended. It is essential that the different cultural idiosyncrasies are translated correctly as otherwise this could give rise to misinterpretations and misunderstandings.

\subsection{Main Research Questions}

The following research questions were constructed:

1. What is meant by effective communication?

2. What is meant by intercultural communication?

3. Does a potential shortcoming exist between how young people communicate in the Czech Republic now and how they should communicate?

4. How can the outcomes from this research be practically applied by social psychologists to help young people in the Czech Republic improve their communication styles and skills?

\section{Research Methodology}

\subsection{Method}

The researchers adopted a constructivist interpretivist research approach within the research 
paradigm of phenomenology. This was considered most appropriate to ensure that the outcome of this research makes a contribution to knowledge that is of value to both academics and the community of practice in the areas of social psychology and psychology in general. In this context, the researchers considered that the world is socially constructed and that, as such, it was important to concentrate on the activities of people within this socially-constructed world and what practical difference social psychology could actually make, for example, to how young people communicate in the Czech Republic today. The researchers adopted the view that reality is subjective and as such the outcome from the face to face interviews support this position. It was therefore imperative and defendable to investigate the perceptions of people within this socially-constructed environment. Fig. 3 is a summary of the research design process.

\begin{tabular}{|c|c|c|c|c|}
\hline \multicolumn{3}{|c|}{ 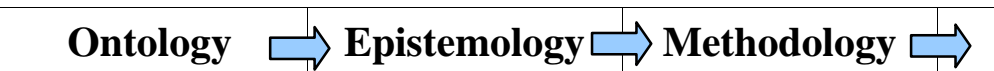 } & Methods $\Rightarrow$ & $\lambda \quad$ Sources \\
\hline $\begin{array}{l}\text { What is out there } \\
\text { to know? }\end{array}$ & $\begin{array}{l}\text { What and how } \\
\text { can we know } \\
\text { about it? }\end{array}$ & $\begin{array}{l}\text { How can we go } \\
\text { about acquiring } \\
\text { it? }\end{array}$ & $\begin{array}{l}\text { Which precise } \\
\text { procedure can we } \\
\text { use to acquire it? }\end{array}$ & $\begin{array}{l}\text { Which data can we } \\
\text { collect? }\end{array}$ \\
\hline
\end{tabular}

Fig. 3 Research Design and Process

The authors, who have many years of theoretical and practical work experience between them, were acting as participatory observers to facilitate this research. 17 undergraduate students in Olomouc, Czech Republic, participated in this research outside of formal teaching hours. They were aged between 19 and 26 years. 8 were male and 9 were female students. Their average age was 23 years. The majority of students were second and third year students (50\%). All participants agreed that real names should be used to give this research a higher level of authenticity. The interviews were conducted in Olomouc, Czech Republic, between July and September 2014. All interviews were recorded word by word to ensure that all responses were captured correctly, including meaning as intended. Interviews were semi-structured. The interviewees were asked for their personal practical and theoretical knowledge and experience to answer the main research questions from Section 1.3. Table 3 is a summary of the questions the researchers asked the students during the face to face interviews. The prime objective of the face to face interviews was to gain contemporary insights from the students and then compare this with the research data from the literature review to verify if the literature review data was valid and relevant for this research.

Table 2 Research Questionnaire

1. How do young people aged between 19 and 26 years of age communicate with people of their own age?

2. How do young people aged between 19 and 26 years of age communicate with older people $(26+)$ ?

3. What communication styles do young people use and which ones to they prefer to use? Explain why they like one style more than another.

4. How do the attitudes young people hold affect how they communicate? How do their attitudes influence how they communicate?

Explain your reasons.

5. What is the difference between how young people who care for others communicate and how young people who do not care for others communicate? Why is this so?

6 . How has the communication style of young people been influenced by the availability of communication technology such as mobile phones, Internet and online social media? How are the communications of young 
people influenced by peer pressure?

7. How do you think young people will communicate in future?

\subsection{Data Collection and Interpretation}

The researchers applied two methods to collect relevant research data to answer the main research questions from Section 1.3: a review of the literature (Section 1.2) and face to face interviews (Section 3.2). They acted as participant observers and added their own contributions and interpretations of what effective and intercultural communications are. This enabled the researchers to gather different viewpoints of the phenomenon under scrutiny. All research data was collected over a period of three months. The outcome of each research method such as literature review and face to face interviews made incremental contributions to the quest to answer the research questions from Section 1.3. The findings from each of the research methods such as literature review and face to face interviews was based on the strength of the evidence from the interpretation and analysis of this data from each of the research methods. It provided the contemporary insights of the interviewees which allowed balanced views of the phenomenon under investigation. The researchers gained the trust of the interviewees in the face to face interviews by conducting all face to face interviews in a consistent professional and structured manner. They captured all research data efficiently by writing down relevant answers verbatim. They probed for further and more in depth information when interviewees failed to volunteer to share more details. It was therefore possible to achieve high levels of data reliability and validity. Fig. 4 shows the whole research design process in a diagrammatical format.

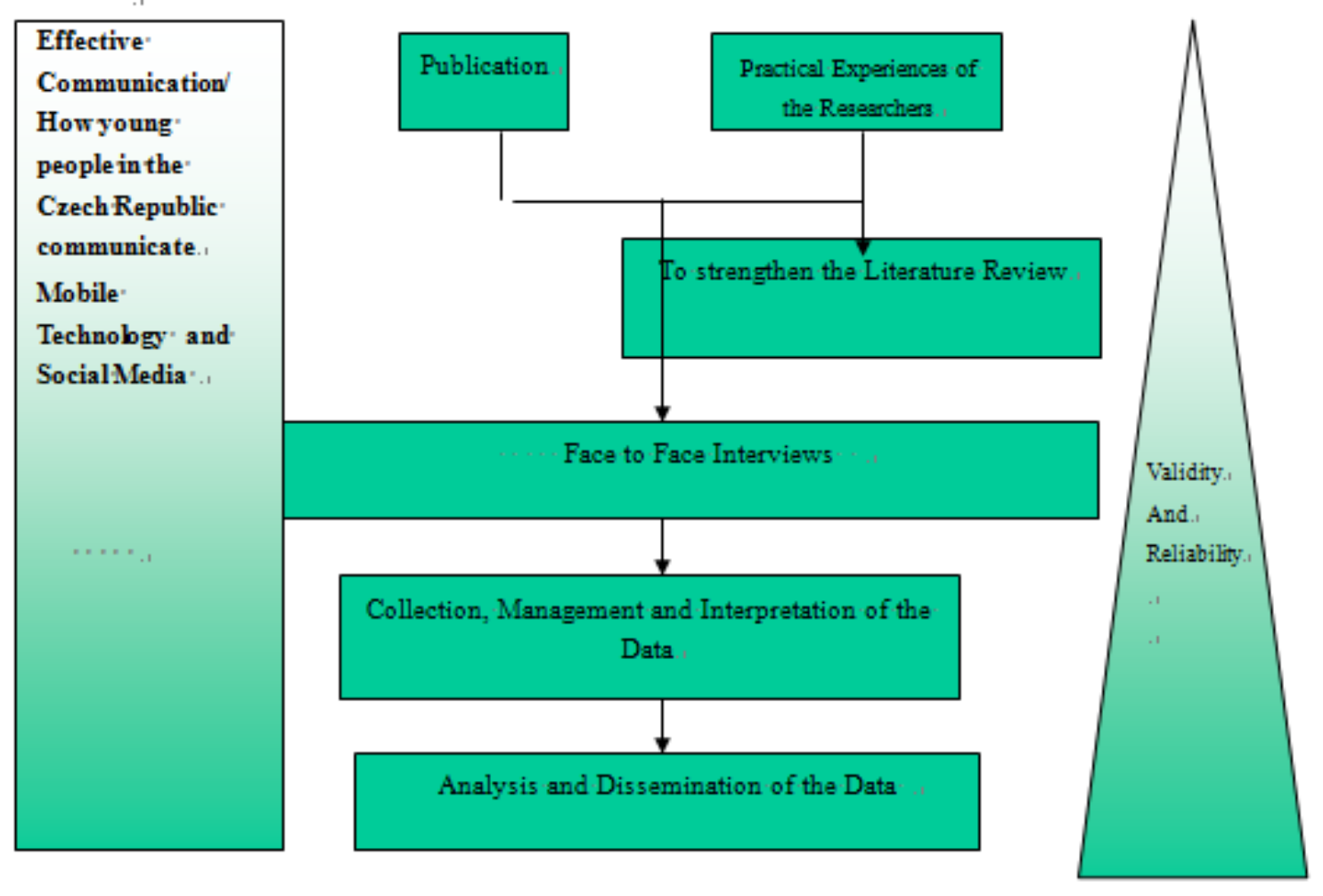

Literature.

Empirical-Material.

Fig. 4. Research Design Process Diagram (adapted from Blackburn, 2001) 


\section{Results}

\subsection{Literature Review}

Current knowledge and thinking from the literature review reveals that communication is important to how human beings are able to cope with the intricacies of the socially constructed world people experience and know. Communication is not limited to sending messages between the sender and the recipient of these messages. Messages sent have to be interpreted correctly and as intended by the sender of the messages. By connecting the feelings, emotions and cultural values of people it is possible to interpret meanings well and as intended. Language itself plays an important role in this process. The spoken word improves the strength of communications and complements the elements of non-verbal communication well such as body language, power distance and smells. Observing human behaviour is an essential activity during communications that will help the listener to make judgments whether someone is lying or actually telling the truth and whether it is possible to trust this person. It is difficult to lie through the use of body language. Another valuable element of effective communications is eye contact. Keeping regular eye contact during conversations, for example, can give some clues as to whether the other person is feeling comfortable talking about the subject matter of the discussion. The observation of gestures, some authors suggest, forms an important element of effective communications. Gestures give an indication how the other person feels and whether the subject matter of the conversation is of interest to them. It appears that this is true to say particularly in some cultural environments where gestures are of paramount importance and sometimes replacing the spoken word. Some authors consider that the positive effect of non-verbal communication is an essential knowledge for people to have and apply if they wish to improve their effective communication skills. This is of high value in communities that are made up of people from different cultural backgrounds. The outcome of the literature review did not provide sufficient evidence what the communication styles of young people are, how these affect how they communicate with others and if their communication styles have a negative impact on sending both message and meaning to the recipients of messages. This will be addressed in Section 3.2 where the results of face to face interviews with young people will be discussed.

\subsection{Face to Face Interviews}

1. How do young people aged between 19 and 26 years of age communicate with people of their own age? 'They communicate through a combination of face to face, telephone, E-mail and Messenger Services' (Jan). 'They are using mainly electronic means of communication such as Facebook and smart phone' (Andrea). 'Young people communicate mainly from a distance using their mobile or social media' (Martina). 'People are overwhelmed by smart phones and all possible chat applications' (Hana). 'Using popular applications such as Viber, Hangouts and Whats App. Smart phones are used for daily communications, E-mails for work stuff and calling for urgent things' (Marek). '18-19 year olds use a very arrogant form of communication. If they do not change their arrogant style, they will have a problem in future. They hear the voice but they do not listen to the content' (Michal). 'How young people communicate depends on their social and educational upbringing. Communications are still 
face to face but boys and girls use lots of vulgar words nowadays' (Robert). 'It appears that that young people spend a lot of their time using electronic applications to communicate, perhaps as much as $70 \%$ of the young people fall into this category, with the remainder (30\%) talking to each other face to face' (Tomas).

2. How do young people aged between 19 and 26 years of age communicate with older people $(26+)$ ? 'I think they prefer face to face communication' (Jan). 'This depends on who they are talking to. For example, when they want to talk to their grandparents, they are most likely to call them on the phone or visit them in person. This applies equally when they wish to communicate with their parents. I also think that students in general are very lazy to find information to do with their studies. They expect others to do it for them' (Martina). 'They will probably use the mobile phone' (Klara). 'With respect and often like peers' (Tomas). 'With some conservative people such as grandparents they will probably communicate by letter' (Robert). ' They balance their communication style depending on the age group of the audience, as some older people (50+) what to be seen to understand and use new technology' (Tomas).

3. What communication styles do young people use and which ones to they prefer to use? Explain why they like one style more than another. 'Indirect communications seem to be the medium to communicate unpleasant things, using social media like Facebook as the so-called middle-man' Some young people still prefer to face to face contacts' (Jan). 'Young people prefer distant communications more and more. Those who write negative things do not face any reaction you might expect in face to face communications. This style is becoming more popular amongst young people' (Martina). 'It seems that face to face talks are slowly disappearing and are being replaced by technology' (Klara). 'Mobile phone tariffs such as unlimited minutes and texts are probably a major contribution factor why so many young people now communicate electronically, via social media and mobile phones' (Tomas). 'Technology provides anonymity. Young people do not have to express their opinions face to face' (Dana). 'Young people use social media to hide behind problems rather than face them' (Barbora). ' I always communicate face to face as I like to see the non-verbal reply so I can make any necessary amendments or adjustments to what I said' (Robert). 'It is a mixture-some people need to communicate face to face, others need to put it in writing' (Tomas). 'Some people like to get acquainted with virtual friends using virtual communications such as social media' (Tomas).

4. How do the attitudes young people hold affect how they communicate? How do their attitudes influence how they communicate?

Explain your reasons. 'Modern technology creates a big gap. Everyone is a hero on the Internet but most people cannot manage to resolve simple real life problems with others' (Jan). 'I believe that people are developing negative attitudes due to the increasing use of social media. If people get cyber bullied or negative comments are made about them, they can react positively by, for example, blocking the other person, deleting comments or simply ignoring it. Some youngsters are obsessed with getting as many 'Likes' as possible. They build their self-confidence on their social media popularity and they cannot live without it' (Veronika). 'Introverts prefer to communicate through social media-it is easier for them. On the other hand, 
extroverts are more likely to go out and talk face to face' (Hana). 'Young people now communicate bad news much more via social media. They feel safer this way as they do not have to see the direct reactions of the other person (s). They can wait to read the answer much later' (Michal). 'In face to face communications, I am more sensitive to the actual feelings of my communication partner. I fully concentrate on what I need and what to say in written communications, bearing in mind my audience. For immediate communications, I prefer face to face or telephone conversations. I judge people by their written communications' (Robert). 'It is very easy to tell lies in virtual communications. You can lie about who you are and what your job is. You can be anyone you wish to be' (Tomas).

5. What is the difference between how young people who care for others communicate and how young people who do not care for others communicate? Why is this so? 'People who really care about communicating with others, will always make an effort to see them face to face or at least call them on the phone or via Skype' (Jan). 'I think that those who care about others usually answer their calls, text or social media messages. The egoist will not answer unless there is something of benefit to them in this '(Veronika). 'It is about taking an interest in other people and hearing what they are saying. People are self-centred in today's world. I surround myself with people who are not self-centred and I can communicate with these people quite easily' (Hana). 'People who really care about others will always use face to face communications' (Marek). 'I think it's all about the relationship between the communication and partners and showing respect' (Dana). 'It's all about caring for others and not just paying lip service. People who care and take care of others focus on society as a whole. They are emphatic and show feelings towards others openly, mostly in face to face encounters' (Tomas). 'Those who really care about others put some form of emotions into their communication, asking questions how others are and how they feel. This is also extended to indirect communications such as text or E-mail, using graphics such as Smiley' (Tomas).

6. How has the communication style of young people been influenced by the availability of communication technology such as mobile phones, Internet and online social media? How are the communications of young people influenced by peer pressure? 'Peer pressure is huge. If you do not use social media, you do not exist. You will miss out frequently on what is going on around you and especially your friends' (Jan). 'Communicating has become more superficial, impersonal and cold. Everyone is expected to be 'cool'. Without a smart phone you cannot be a member of a social circle. Social media can also be used effectively to share relevant information on E-rooms such as Alfresco at many universities' (Andrea). 'Peer pressure is enormous and young peoples' communication style has been influenced in such a way that they often use short codes or short cuts to convey messages, using mainly English' (Martina). 'Everything is online. Sometimes I go out with people and they continue to chat online with others while I am talking to them. Their eyes are fixed on the mobile phone display whilst talking to me. This is very sad indeed' (Veronica). 'Even young children cannot help it but constantly looking at the screens of their mobile or smart phones. Peer pressure is very strong. Belong or be alone seems to be the order of the day' (Hana). 'I think it is up to each person to make the most of it and to make it work for them. It is up to each individual' (Tomas). 'A lot of communications take place that are meaningless because young people feel the need to just 
'chat'. Technology has made this easier for them' (Alena).

7. How do you think young people will communicate in future? 'I think there will be less and less personal contact in all communications' (Jan). 'Newer technology will enable us to communicate via holograms and all communications will be cold. There will be less personal contact' (Andrea, Tomas). 'I personally hope that people will learn more about the boundary between personal and social life. I hope that they will use technology for their benefit and not just to get the attention of others. I hope that simple face to face communications will not die. You cannot replace an actual laugh or smile with an electronic one' (Veronica). 'I am optimistic that technologies will spread more but that people will continue to communicate in the classic face to face style' (Hana).' Most communications will be transmitted through Google Glass and by using our own thoughts' (Klara, Marek). 'Electronic communications will be stronger and 'the letter' will die' (Alena).

\section{Discussion}

The recent introduction of new and attractive mobile phone contracts has had a major impact on how young people communicate in the Czech Republic. Unlimited minutes, texts and data have become popular with young people and users are no longer restricted, for example, how long they connect to social media or the Internet, how many text messages they are sending or how long they talk on the phone. It appears that this has had a major impact on the communication style and behaviour of young people. Face to face communications have been overtaken by social media and text messaging as a means of primary communication with peer groups and older people. The primary means of communication used to be face to face. This had a number of advantages. Young people had more time to think about what to communicate, what style to use such as direct or softly-softly approach and when to communicate, for example, leaving a few hours between receiving an emotional outburst and responding to it. They could also tell from the intonation of voice, for example, whether a message was meant to be serious or whether the sender was simply joking. It is also easy to lie through the spoken word but it is more difficult to lie through body language. Body language can only be observed in direct face to face communication including Skype and Video-Conferencing.

There is evidence from the face to face interviews that suggests that a widening gap is developing between direct and virtual communication styles. The number of young people who are beginning to lose the ability to communicate effectively with others face to face is rising. Older people are finding it more difficult today to communicate directly with young people and to pass on their knowledge and experience to them. There is a growing danger that young people, over time, will not be able to develop their skills, for example, as effectively as they used to in the past. This outcome of this research has shown that young people have already started to distance themselves more and more from older members of the communities they live in. In turn, this has an adverse effect on how well these communities live together and go about their daily lives. This includes the achievements of common goals and objectives. A recent study conducted by Fisher and Santana González (2014) about how young people in Cuba communicate, reported a similar developing trend how communities lose out due to diminishing face to face communications by young people. 
A communication can only be effective when both the sender and receiver of the intended message clearly understand what is being communicated. The adopted communication style of young people, for example, of sending coded and short messages such as SMS or Twitter, does not constitute effective communications. This is true to say as far as older people are concerned. Within their own peer groups, it appears that this communication style is effective and that sender and receiver understand each other. This may not be effective in cross-cultural communications. Many young Czech people travel to other countries and interact with peer groups from other cultures. What works well in one culture does not necessarily work equally well in another including same or similar age groups. For example, short codes used in one cultural environment can have a totally different meaning when used with people from another culture, such as LOL (can mean Lots of Love or Laughing Out Loud). This applies equally to the use of sign language and symbols. For example, forming a circle with the thumb and first finger means 'Well Done' or 'Excellent' in some cultures but in others it means You Are An Idiot (used sometimes by car drivers when another car driver has misbehaved).

The arrival and use of new technology is not all negative. It enables young people to have access to information much faster, irrespective of their location and the time zone they are in. They can share information, for example, with other young people and friends from across the world in many formats such as text, pictures and video clips. When used properly and appropriately, the new technological advances make a major contribution to enhance the lives of young people in the Czech Republic both at social and work levels.

\section{Conclusions}

Advances in technology continue to grow at a fast pace, providing what seem to be endless means of being able to communicate almost anything with anyone anywhere in the world at any time. When used appropriately, this advance in technology will have a positive effect on how young people communicate in the Czech Republic. Young people communicate primarily through the use of Internet, social media and mobile telephony. This has a direct influence on their communication and life styles. These, in turn, affect how they communicate not just within their peer groups but also with older members of the communities they live and work in. Young people need to develop a better comprehension of what the likely consequences are for inappropriate behaviour and actions as far as communications are concerned in areas such as social media, the Internet and mobile telephony. It is equally important that young people understand that they are, and certainly should be, in control of all their communications. They should not allow others to distract them adversely nor should they adopt unsuitable communication styles such as communicating with older people by adopting an SMS type communication style that is short and shows no respect but is driven by peer pressure to 'act differently'. Social Psychology and Psychology have a vital and pivotal role to play to educate young people how to communicate effectively with others and how to stay in control of their communications in an era of cyber bullying and misuse of mobile technology. Psychology and Social Psychology need to make substantive contributions to help young people and guide them how to use mobile technology and social media appropriately and how to stay in control of their communications with people of all age groups and cross-culturally. Actions speak louder than words. These actions could take many forms. Proactive activities need to include 
interactive presentations at schools, colleges and universities to educate young people in the appropriate use of the new and emerging technologies. Psychology and Social Psychology teachers and students could interact with young people at weekends, for example, in the town centre of Olomouc, initially, to drive home their important messages and to capture the attention of young people. If successful, this could be rolled out across the country later. This research has been limited to how young people communicate in Olomouc, Czech Republic. It would be interesting to conduct further research in other cities across the Czech Republic to establish whether the findings from Olomouc hold true as representative samples for the whole of the Czech Republic. It is confirmed that the research questions from Section 1.3 have been answered.

\section{Acknowledgements}

The corresponding author wishes to thank the Palacky University in Olomouc, Czech Republic, for providing access to interview students from the Faculty of Psychology outside of formal teaching hours to assist with the completion of this research.

\section{References}

Bakir A., Landis, D., \& Noguchi, K. (2004). Looking Into Studies of Heterogeneous Small Groups. An Analysis of the Research Finding, Landis

Blackburn, S. (2001). Understanding Project Managers At Work, Henley Management College/Brunel University, DBA Thesis

Chevrier S. (2003). Cross-Cultural Management in Multinational Project Groups, Journal of World Business, No 38

Chiper, S. (2013). Teaching intercultural comminications: ICT resources and best practices, Procedia-Social and Behavioral Sciences, 93, 1641-1645, Elsevier, http://dx.doi.org/10.1016/j.sbspro.2013.10.094

Cox T, Blake S. (1991). Managing Cultural Diversity: Implications for Organizational Competitiveness, Academy of Management, No 5

Dinica, R. C. (2014). Non-verbal communication -indispensable complement of oral and written communication, Procedia-Social and Behavioral Sciences, 137(2014), 105-111, Elsevier, http://dx.doi.org/10.1016/j.sbspro.2014.05.260

Fisher, E. (2013). From Cyber Bullying To Cyber Coping: The Misuse of Mobile Technology and Social Media and Their Effects on People's Lives, Business and Economic Research, 3(2), 127-145, http://dx.doi.org/10.5296/ber.v3i2.4176

Fisher, E., \& Santana González, Y. (2014). How Young People Communicate-A Cuban Perspective, International Scientific Conference, Olomouc, Czech Republic

Giant, N. (2013). E-Safety For The i-Generation-Combating The Misuse and Abuse Of Technology In Schools, Jessica Kingsley Publishers

Goodall, K., \& Roberts, J. (2003).Only Connect: Teamwork in the Multinational, Journal of 
World Business, No 38

Hall, E. T. (1966).The Hidden Dimension, New York, Doubleday http://slovnik-cizich-slov.abz.cz/web.php/slovo/efektivni-komunikace

Ivancevich, J. M., \& Matteson, M. T. (1992). Organizational Behaviour and Management, Third Edition, Irwin

Jandt, F. E. (2001). Intercultural Communication-An Introduction, Third Edition, Sage Publications

Lewis, R. D. (1996). When Cultures Collide. Managing successfully across cultures, London, Nicholas Brealey Publishing

Maletzke, G. (1976). Sicologia de la Comunicacion, Editorial Epoca, Quito

Moore, D. R, Cheng, M.-I., \& Dainty, A. R. J. (2002). Competence, competency and competencies: performance assessment in organisations, Work Study: A Journal of Productivity Science, 51(6), 314-319

Pinto, R. Z., Ferreira, M. L., Oliveira, V. C., Franco, M. R., Adams, R., Maher, C. G., \& Ferreira, P. H. (2012). Patient-centred communication is associated with positive therapeutic alliance; a systematic review, Journal of Physiotherapy, 58, 77-87, Australian Physiotherapy Association, http://dx.doi.org/10.1016/S1836-9553(12)70087-5

Popescu, A.-D., Suciu, S., \& Raoult, M.-G.(2014). Intercultural competences in collaborative teams, Procedia Technology, Science Direct, 12, 577-582

Reber, A. S. (1995). Dictionary of Psychology, Penguin Books

Rogers, V. (2010). Cyber Bullying-Activities To Help Children And Teens To Stay Safe In A Texting, Twittering, Social Networking World, Jessica Kingsley Publishers

Rogers, E. M., \& Steinfatt, T. M. (1999). Intercultural Communication, Waveland Press, Inc.

Stanton, N. (1995). Comunicarea, Bucuresti: Societatea Stiinta si Technica SA

Thomson, P. (1996). The Secrets Of Communication,Simon\&Schuster Ltd.

Ury, W. (1994). Dincolo de refuz, Timisoara: Editura de Vest

\section{Copyright Disclaimer}

Copyright reserved by the author(s).

This article is an open-access article distributed under the terms and conditions of the Creative Commons Attribution license (http://creativecommons.org/licenses/by/3.0/). 